\author{
ANNALS OF “DUNAREA DE JOS” UNIVERSITY OF GALATI \\ MATHEMATICS, PHYSICS, THEORETICAL MECHANICS \\ FASCICLE II, YEAR XI (XLII) 2019, No. 2
}

DOI: https://doi.org/10.35219/ann-ugal-math-phys-mec.2019.2.03

\title{
DETECTING RIVERBANK CHANGES WITH REMOTE SENSING TOOLS. CASE STUDY: AGGITIS RIVER IN GREECE
}

\author{
Paschalis Koutalakis ${ }^{1}$, Ourania Tzoraki ${ }^{2}$, George N. Zaimes ${ }^{3, *}$ \\ ${ }^{I}$ PhD Student, Department of Marine Sciences, University of Aegean, Mytilene, GREECE \\ ${ }^{2}$ Assistant Professor, Department of Marine Sciences, University of Aegean, Mytilene, GREECE \\ ${ }^{3}$ Deputy Chair, UNESCO Chair Con-E-Ect, Conservation and Ecotourism of Riparian and Deltaic Ecosystems \\ and Assistant Professor, Laboratory of Geomorphology, Edaphology and Riparian Areas (GERi), Department \\ of Forestry and Natural Environment, International Hellenic University (IHU), $1^{s t} \mathrm{~km}$ Drama-Microhoriou, \\ Drama, 66100, GREECE, \\ *Corresponding author: zaimesg@teiemt.gr
}

\begin{abstract}
Fluviogeomorphologic processes such as bank erosion and deposition affect and change the shape and condition of river and stream channels. Erosion and deposition rates are dependent on many natural (e.g. climate, geology, vegetation, topography) and anthropogenic (e.g. dams, bridges, gabions, straightening, wildfires etc.) factors. Alterations to these factors disrupt the rivers/streams dynamic equilibrium and they respond by altering their shape, formation or even location. These changes might be slow or rapid but can cause serious problems to infrastructures and lead to loss of human lives. For the more effective and sustainable management of rivers or stream and in general watersheds, new innovative methods are needed to monitor and understand these fluviogeomorphologic processes. Remote sensing tools can be utilized to monitor, predict and measure such changes in rivers and streams. Free satellite images and ortho-maps generated by airplanes have been used worldwide to map geomorphologic changes through time. Ortho-images captured by drone flights are more effective because their higher spatial resolution they provide compared to satellite or airplane images can provide more details on the river or stream. The use of drone images can be low cost, thus provide an effiecint way to map riverbank changes in targeted reaches that face erosional or depositional problems. This study used remote sensing tools to identify river banks changes by combining free satellite, aerial and low flight drone images. The study areas were reaches along Aggitis River in northern Greece. Firstly, free satellite and Google Earth images were utilized to map the entire watershed and find at a large scale the potential riverbank reaches that have had changes (erosion and/or deposition). Secondly, drone flights were executed to acquire high resolution images at a specific location (having erosion). Through these images, it was determined more accurately if accelerated bank erosion or deposition were occurring. Overall, these remote sensing tools proved to be a quick and low-cost methodology that allows identifying and measuring stream bank changes over many years but also over short periods of time (e.g. after a flood event). In addition, the methodology enables us to locate the areas with the greatest potential of erosion and deposition where nature-based solution should be implemented to stabilize stream banks, reduce erosion or deposition rates and mitigate nonpoint source pollutants. This paper was presented at the MONITOX International Symposium "Deltas and Wetlands", Tulcea, Romania, 15-17 September, 2019.
\end{abstract}

Keywords: drone images, satellite images, geomorphology, UAV, stream bank erosion

\section{INTRODUCTION}

The river and stream channels of watersheds change constantly in order to maintain their dynamic equilibrium [1]. Typically these changes depend on the watershed characteristics (e.g. climate, geology, vegetation, topography). If these characteristics are not modified, these fluviogeomorphologic processes 
are within natural limits [2]. But anthropogenic changes (e.g. dams, bridges) and disasters (e.g. wildfires) can exacerbate these changes $[3,4]$.

Erosion and deposition are two of these main fluviogeomorphologic processes that are expressed either at the watershed scale or in the stream channels. Natural stream bank erosion and deposition can enhance biodiversity (e.g. increase plant diversity) in riparian areas [5]. In contrast, accelerated stream bank erosion and deposition due to anthropogenic activities can increase sedimentation downstream that degrades aquatic habitats, reduces water quality and increases flood risk, leading to substantial losses of agricultural land and adjacent structures and is considered a hazard since floods can cause loss of life and property [6-8]. Increasing stream bank stability has been a major priority for decades with large amounts of money spent on watershed conservation and stream channel restoration projects [9].

To evaluate and monitor the impacts of anthropogenic activities on stream bank erosion, siteassessments and in-situ measurements have traditionally been used [10., 11]. These types of approaches can be laborious, resource demanding and time consuming, especially when examining lengthy reaches of rivers or streams. The technological and methodological advancements in the field of Earth Observation (EO), has contributed to the widespread increase in the use of satellite remote sensing approaches that have enhanced the monitoring of the Earth's surface [12]. Today there is a readily available large collection of imagery in Google Earth, including satellite, aerial, but even 3D, and Street View images. The latest developments in the field are the Unmanned Aerial Vehicles (UAVs). UAVs also known as drones are flying machines that are not equipped with any pilot on board and are controlled by a person on the ground [13]. For this reason, drones provide safe but also low cost high spatial resolution images [14]. Drones have been used in natural environments such as rivers or streams for hydrologic purposes to estimate water velocity and discharge [15]. These tools are now starting to be utilized to their full potential in regard to fluviogeomorphologic processes and stream bank erosion and deposition.

Another advantage of utilizing these tools is to enable land managers to identify "hot-spots" of stream bank erosion and deposition. Limited financial resources require focusing the implementation of management practices in the hot spots that are the major sediment sources. Diebel et al. [16] found that by targeting the areas that produce the highest $10 \%$ of sediment, the watershed stream sediment loads were reduced by $20 \%$. The objective of this study was to assess the use of remote sensing and UAV images in order to identify and measure stream bank changes over short period of time and to locate the areas of stream bank erosion and deposition where nature-based solution should be implemented to stabilize the stream banks.

\section{MATERIALS AND METHODS}

\subsection{The Study Area}

The study focused on a reach of Aggitis River. Aggitis River is the main tributary of the transboundary Strymonas River (Bulgaria, Greece and FYROM) [17]. Aggitis Basin covers an area of $2234 \mathrm{~km}^{2}[18]$ and it is surrounded to the north by the Falakro mountain, to the east by the Falakro and Lekani mountains, to the south by the Paggaio Mountain and to the west by the Paggaio and Menoikio mountains. The study reach was located near Draviskos Village in North Greece (Lat. 40.940597, Lon. 23.836533). The specific reach was selected because it provides easy accessibility since the riparian vegetation on one side of the riverbank is very low and the road network pass nearby it. There are two bridges before and after the specific reach (Figure 1). During high water discharges, soil erosion is very intense that causes even tree removals (Figure 2). The trees are transported by the river and deposited near the banks or in places where they meet obstacles. The bridges also act as such obstacles for the larger debris. The continuous debris flow creates a great number of trunks, brunches and other natural or even man-made debris (Figure 2) to be collected behind the bridge. 

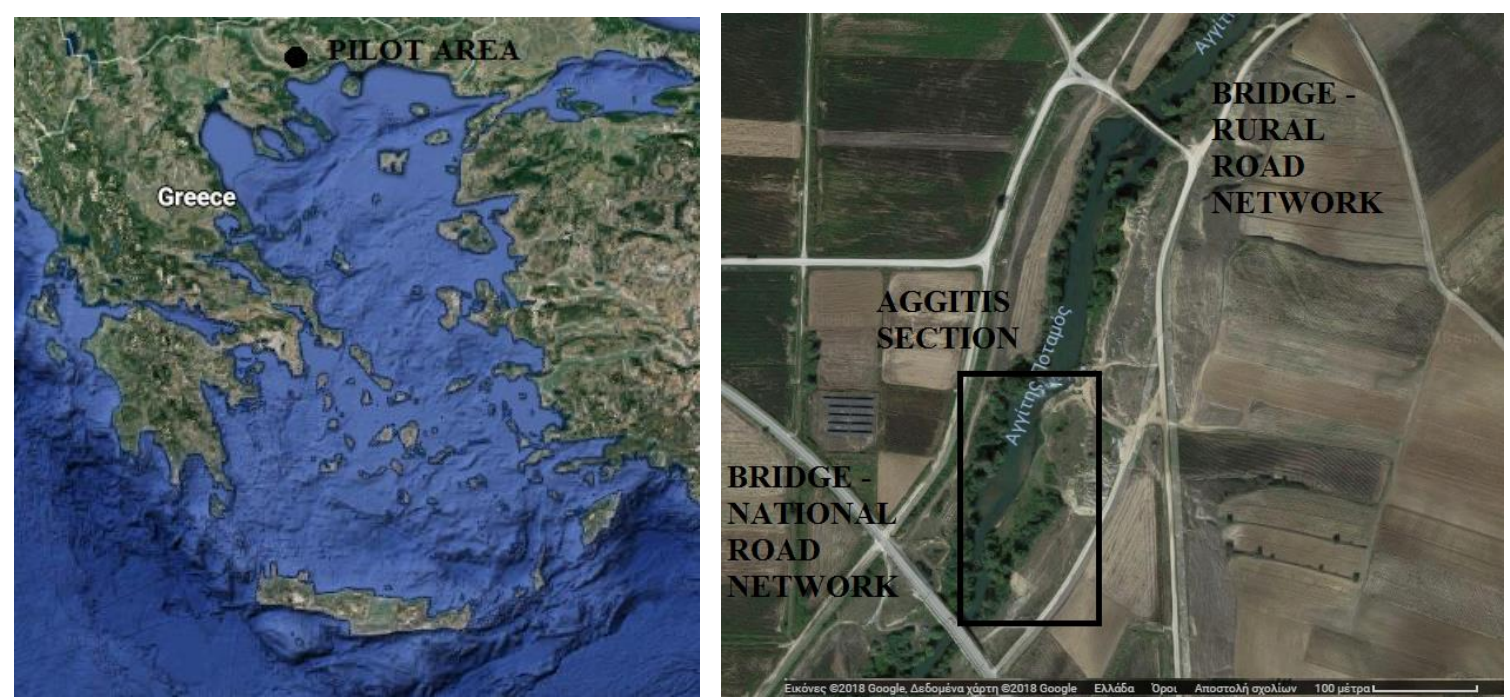

Fig. 1. Aggitis River IN Greece (left) and the studied reach of Aggitis with the neighbouring road network (right) (source: Google Earth).
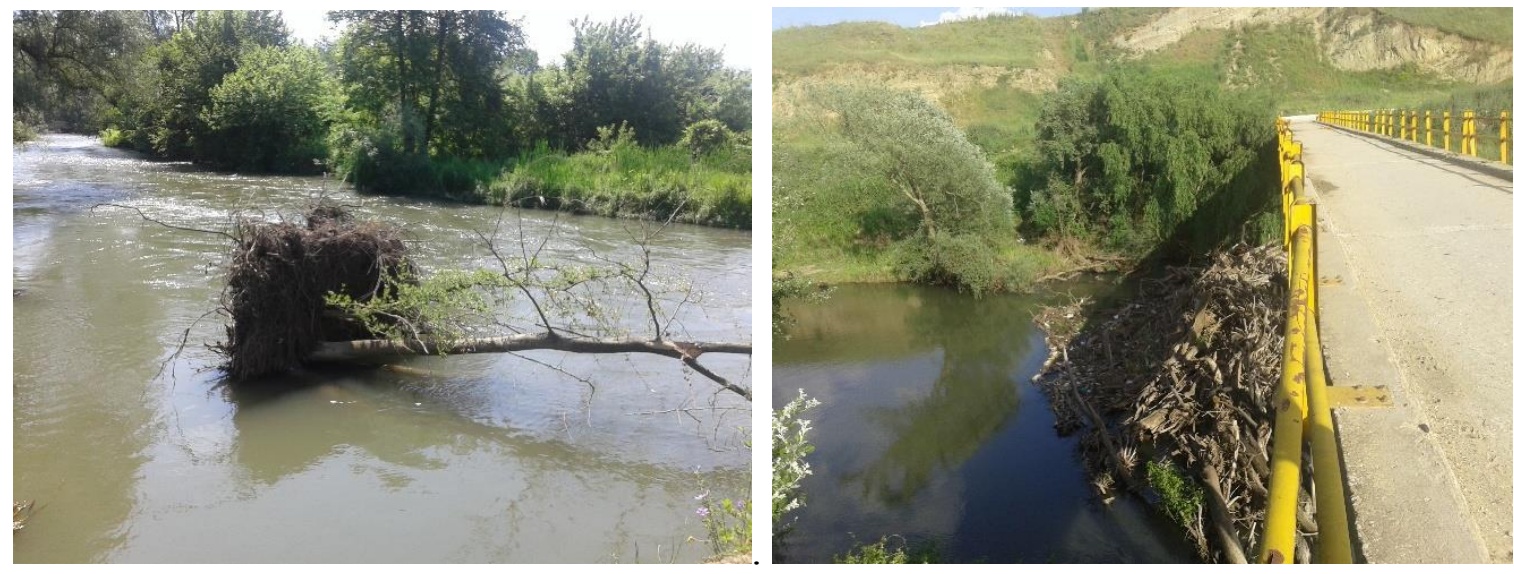

Fig. 2. Tree debris due to soil erosion by high water discharge (left) and debris accumulation at one of the bridges (right).

\subsection{The satellite images}

Satellite images are used widely in remote sensing applications [19] since they provide high spatial resolution but are typically costly. Free satellite images such as Landsat satellites provide valuable information especially where the study area is extensive at lower spatial resolutions. When the study area covers some square meters or even a few square kilometers, it is difficult to acquire free high-quality images by Landsat.

The following images captured by Landsat satellite (Figure 3 ) show the differences between two different periods: a) 30-04-2013 and b) 30-04-2018. During the first period (2013) there was a peak discharge in both Strymonas and Aggitis Rivers (right image of Figure 3). The impact of the peak discharge among the two periods is especially visible in Strymonas River; the larger river of the area. For such areas and/or rivers it is possible to use free satellite images as a first step to compare between different time periods. Changes in Aggitis River are not visible for a non-specialist although there is also a difference of its width and consequently the water discharge. 

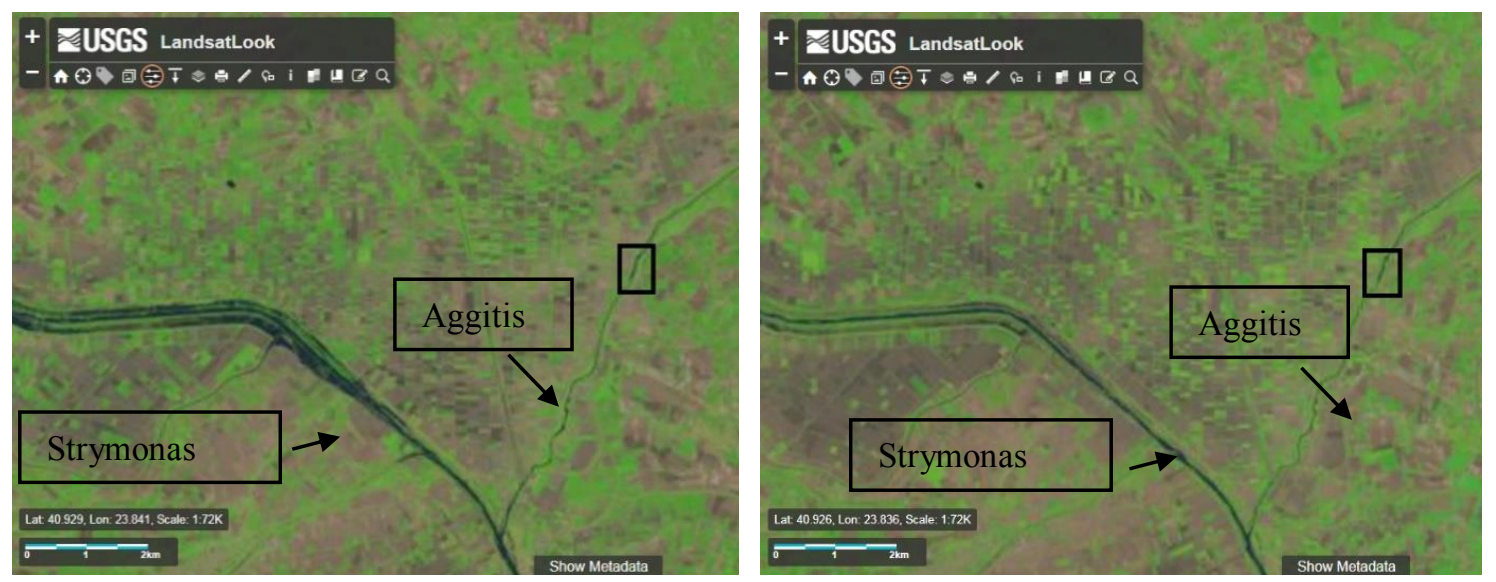

Fig. 3. Satellite images of Strymonas and Aggitis Rivers that depict the changes of different time periods, 30-4-2013 (left) and 30-4-2018 (right). The squared area is the studied cross section of Aggitis (source: Landsat Images).

\subsection{The Google Earth images}

The Google Earth images were also captured during two different time periods. There are many different dates stored in Google Earth Database, but these specific images were selected as they are fully visible (no cloud cover) and represent major geomorphologic changes. The images were captured by airplanes, with the left one depicting the study area at 26-3-2010 and the right one at 1-10-2014 (Figure 4), with both at the same scale. The vegetation is different because of its growth in the second image (2014). Another visible characteristic is the high discharge during the 2010 image. The river banks are wider in 2010 than in 2014, and highly noticeable at the lower part after the bridge but also at the channel over the bridge and at the pipe barrier where waves are generated because of the barrier and the large stones. Another significant change is the appearance of the small island in the 2010 image that was situated at the central part of the reach as depicted by the images and its union to the right bank. The flow of the water is divided into two separate flows because of the low elevation at this location that creates a small island as depicted in the left figure (2010) (Figure 4). The right sector flow is covered by the dense vegetation of trees. The right image (2014) due to the lower discharge (typical baseflow discharge of Aggitis River) did not reveal this island.

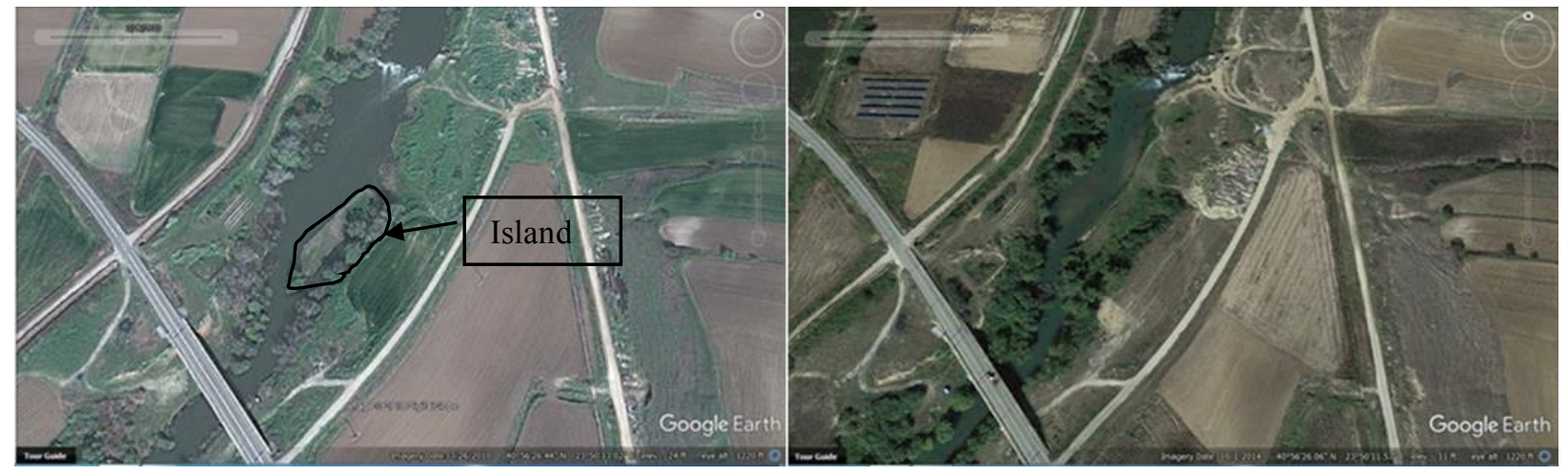

Fig. 4. Images of Aggitis Cross Section that depict the changes of different time periods, 263-2010 (left) and 1-10-2014 (right) (source: Google Earth). 


\subsection{The drone images}

In addition, a drone was utilized in order to acquire higher image quality compared to the satellite and google earth images. The DJI Spark mini drone was selected as a low-cost tool able to acquire images in stable mode and in the proper altitude. Table 1 provides the specifications of the DJI Spark, both its drone and camera. The images were taken during three different days with excellent weather conditions (sunny day with no wind) that had different stream flow conditions. On 8-5-2018 was the first day of acquiring images. On 14-5-2018 that was the second day, since the river discharge increased after many rainy days that resulted in the "muddy" water due to high concentration of soil particles (erosional processes). The third day of flying the drone was 20-7-2018 to depict the discharge and water level change as well as any changes on the river banks after a hotter period that the previous two during the second summer month.

Table 1. DJI Spark Specifications (from https://www.dji.com)

\begin{tabular}{|l|c|l|l|}
\hline \multicolumn{2}{|c|}{ Drone Specifications } & \multicolumn{2}{c|}{ Camera Specifications } \\
\hline Takeoff weight: & $300 \mathrm{gr}$ & Sensor: & $1 / 2.3^{\prime \prime}$ CMOS \\
\hline Dimensions: & $143 \times 143 \times 55 \mathrm{~mm}$ & Lens: & FOV $81.9^{\circ} 25 \mathrm{~mm}$ \\
\hline Max flight time: & $15-166^{\prime}$ & ISO range: & Video: $100-3200$ \\
\hline Satellite positioning: & GPS/GLONASS & Video: & $\begin{array}{l}\text { Resolution: } 1920 \times 1080 \\
30 \mathrm{fps}\end{array}$ \\
\hline Hover accuracy range: & $\begin{array}{l}\text { Vertical }+/-0.1 \mathrm{~m} \\
\text { Horizontal }+/-0.3 \mathrm{~m}\end{array}$ & Format: & $\begin{array}{l}\text { MP4 } \\
\text { AVC/H.264) }\end{array}$ \\
\hline $\begin{array}{l}\text { Max transmission Wi- } \\
\text { Fi distance: }\end{array}$ & $\begin{array}{l}100 \mathrm{~m} \text { distance } \\
\text { 2-axis mechanical (pitch, } \\
\text { roll) }\end{array}$ \\
\hline
\end{tabular}

\subsection{The software utilized}

Firstly, the images captured by the drone were processed in PhotoScan (Agiosoft LLC) software. Agisoft PhotoScan combines digital images in order to create high resolution, scaled and georeferenced 3D models. In addition, Agisoft PhotoScan Professional has functions to generate aerial triangulation, polygonal models (plain/textured), set a coordinate system, georeference DTMs and georeference orthomosaic maps [20]. Agisoft PhotoScan also allows the user to build 3D models and Digital Surface Model (DSM) with different resolutions. The workflow is fully automated and enables a non-specialist to get familiar with it very quickly. Based on the latest multi-view 3D reconstruction technology, it operates with arbitrary images and is efficient in both controlled and uncontrolled conditions [21]. Photos can be captured from any position, providing that the studied object or area is visible on at least two different photos [22]. The total amount of processed images was around 50, for each day that had drone flights. The combination of these 50 images produced the orthomosaics of the studied area. Finally, the produced orthomosaic maps were inputted and edited in ArcGIS 10.4 in order to detect and digitize the changes of river banks among the three different periods.

\section{RESULTS AND DISCUSSION}

Figure 5 depicts the orthomosaic maps created in Agisoft PhotoScan by the combination of the 50 images taken by the drone each day. The left figure of Figure 5 was created by the images captured at 8-5-2018 while the right image represents the conditions at 14-5-2018. In Figure 6, the left image illustrates the orthomosaic at 20-7-2018 while the right one reveals the digitized riverbank changes. The 
blue line depicts the riverbank of 8-5-2018, the red line shows the riverbank of 14-5-2018 and the dark red line represents the riverbank of 20-7-2018. There is only one set of lines (right riverbank) because of the dense vegetation on the left riverbank.
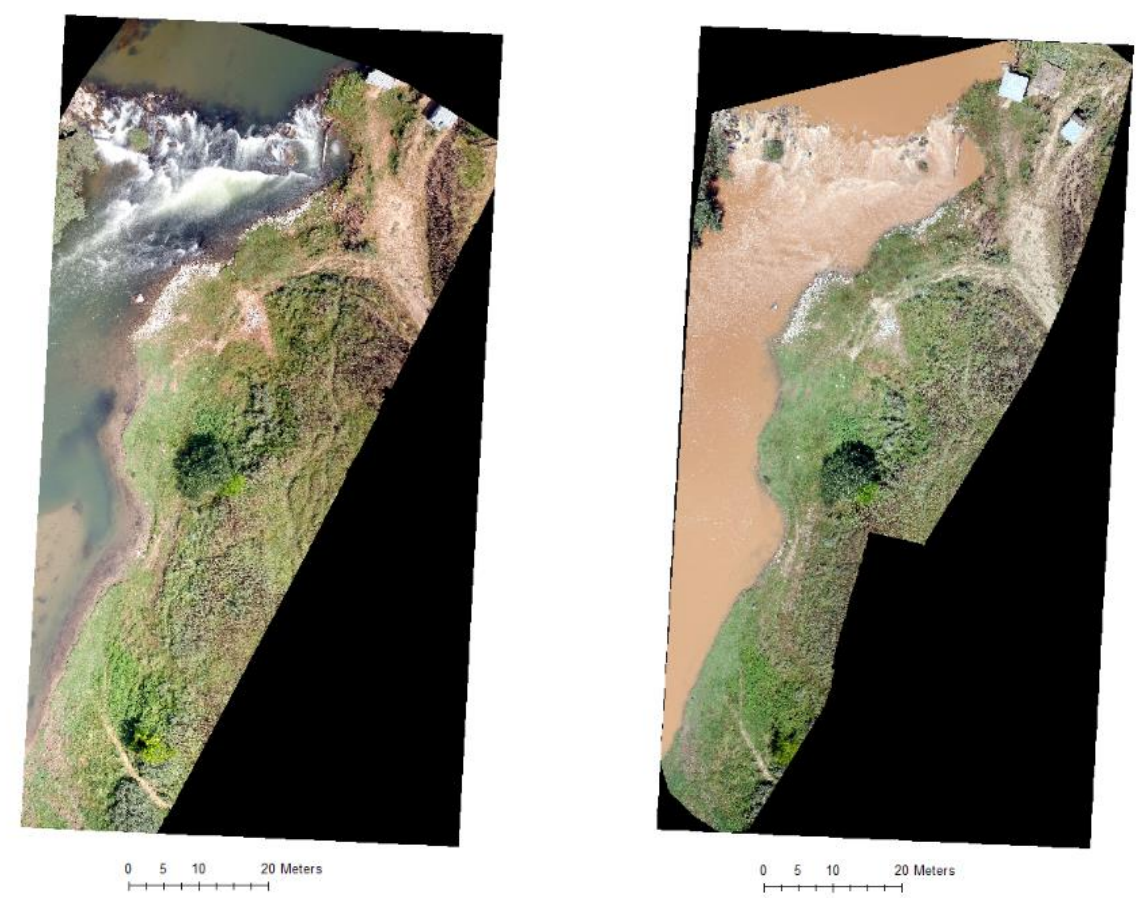

Fig. 5. Orthomosaic maps of the study area from different time periods, 8-5-2018 (left) and 15-5-2018 (right).

Based on the above images, there are visible changes during these three periods. Even a few days later (during the month of May), the high precipitation resulted in a high discharge event that led to a high stream water level. During June and July of 2018 there were also frequent and intense precipitation events but the high temperature caused increased water evaporation and resulted to a lower water level and the revealing of a small island. This island was visible only during the third measurement (20-7-2018), although the clear water (sediment free) during 8-5-2018 also reveals that the depth is low at that location. More intense changes could have been expected if the summer of 2018 was drier (unusually wet).

In addition, the spatial measurements of these changes are very easy to be implemented through the GIS software and to compute the riverbank changes in meters or even square meters. Riverbank changes ranged from 0.2 to even $5 \mathrm{~m}$ at this specific studied location. Of course, the width changes are highly related to the topography. Wider changes were depicted in the hot-spots where the elevation was flatter such as those close to the revealed island. These changes could be better depicted with a 3D model if the images were captured in all angles and at different heights in order to incorporate the elevation information. Although this was not achieved during the specific measurement dates (most images captured by the drone had a parallel view to the surface), a low quality 3D model was possible to be extracted in order to show the capabilities of the Agisoft software by using images captured by a small drone (Figure 7). These 3D images could be utilized in order to locate vulnerable areas and probably combine the results by using other expert software (e.g. AutoCAD) for bioengineering models and works. 

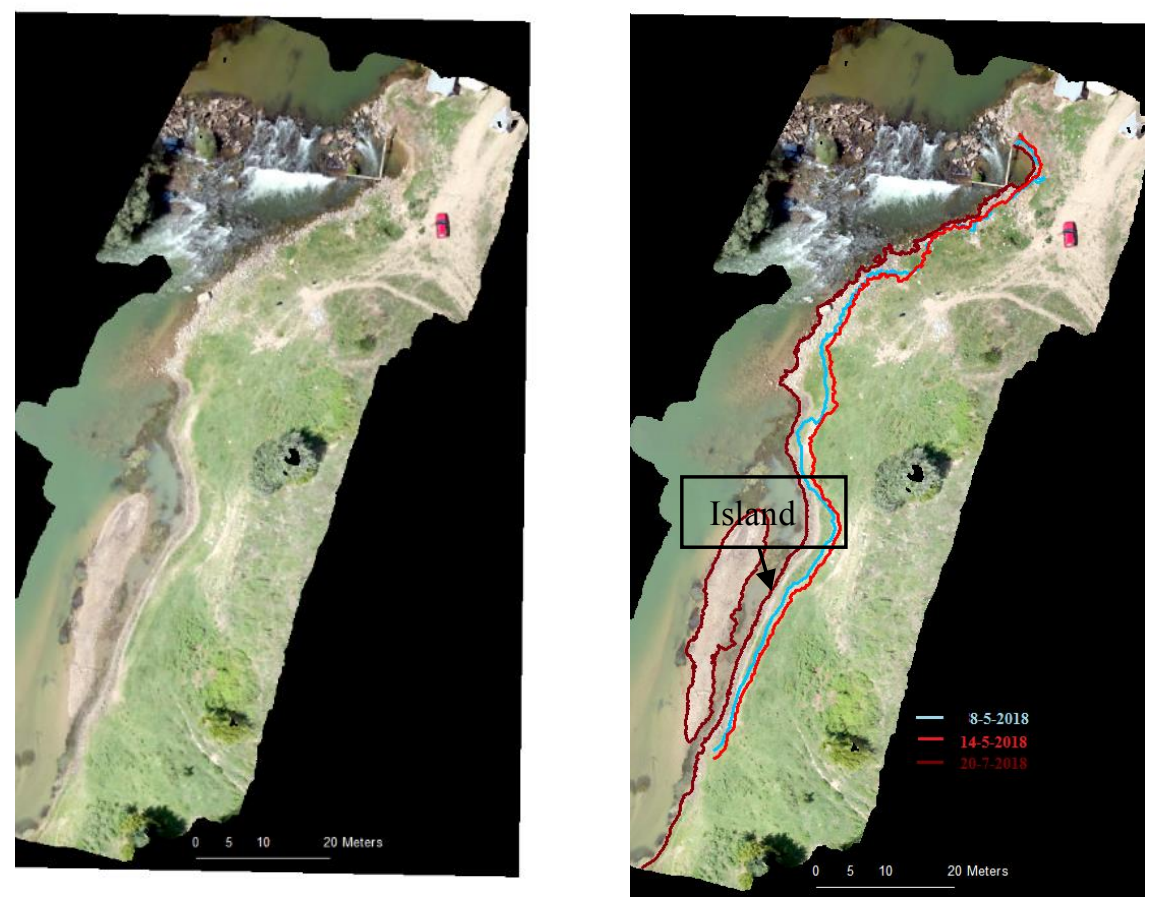

Fig. 6. Orthomosaic map of the study area from 20-7-2018 (left) and the riverbank changes among the three different periods (right) (edited in ArcGIS).

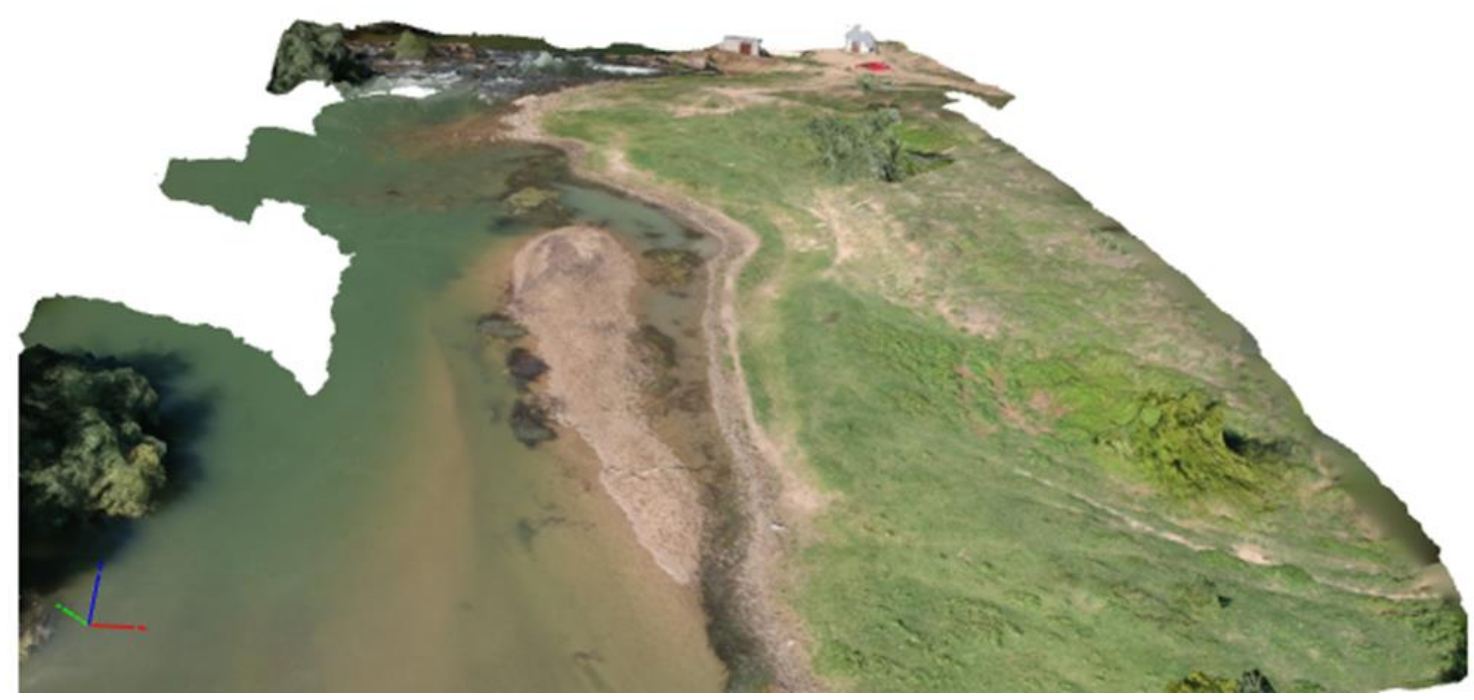

Fig. 7. The 3D model of the study area (20-7-2018) produced in Agisoft Photoscan.

\section{CONCLUSIONS}

Remote sensing products such as free satellite and Google images can be the first step in order to identify riverbank changes over short periods of time (e.g. after a flood event) or over many years. Low cost drones can be utilized as a second step to provide higher accuracy and analysis in larger scale of these specific locations. The images can be combined in order to create the orthomosaic maps and 
further be edited in GIS software to reveal the riverbank changes but also to measure the width and depth. Through these drone images, where accelerated bank erosion or deposition was occurring was determined more accurately. This methodology is user-friendly, low cost (free and low cost tools/software), quick as images can be captured in 10 minutes or less (depending on the area) and the results can be produced in a few hours (depending on the hardware capabilities) but also providing safety as the user can hover the UAV remotely from a distance from the riverbanks and channel. Finally, the methodology enables us to locate the areas with the greatest potential of erosion and deposition where nature-based solution [23] should be implemented by land managers in order to stabilize stream banks, reduce erosion or deposition rates and mitigate nonpoint source pollutants.

\section{References}

1. Tzoraki O., Nikolaidis N.P., Trancoso A.R., Braunschweig F., Neves R., A reach- scale biogeochemical model for temporary rivers. Hydrol. Process. 23(2), 272-283, 2009.

2. Zaimes G.N., Schultz R.C., Isenhart T.M., Riparian land uses and precipitation influences on stream bank erosion in central Iowa. J. Am. Water Resourc. Assoc. 42(1), 83-97, 2006.

3. Koutalakis P., Zaimes G.N., Iakovoglou V., Ioannou K., Reviewing soil erosion in Greece. World Academy of Science, International Journal of Environmental, Chemical, Ecological, Geological and Geophysical Engineering, 9(8), 936-941, 2015.

4. Zaimes G.N., Gounaridis D., Symeonakis E., Assessing the impact of dams on riparian and deltaic vegetation using remotely-sensed vegetation indices and Random Forests modelling. Ecol. Indic. 103, 630-641, 2019.

5. Salo J., Kalliola R., Hakkinen I., Makinen Y., Niemala P., Puhakka M., Coley P.D., River dynamics and the diversity of the Amazon lowland forest. Nature 322(6076), 254-258, 1986.

6. Pinter N., Heine R.A., Hydrodynamic and morphodynamic response to river engineering documented by fixed-discharge analysis, Lower Missouri River, USA. J. Hydrol. 302(1), 70-91, 2005.

7. Owens P.N., Batalla R.J., Collins A.J., Gomez B., Hicks D.M., Horowitz A.J., Kondolf G.M., Marden M., Page M.J., Peacock D.H., Petticrew E.L., Salomons, W., Trustrum N.A., Fine-grained sediment in river systems: Environmental significance and management issues. River Res. Appl. 21, 693-717, 2005.

8. Zaimes G.N., Tufekcioglu M., Schultz R.C. Riparian land-use impacts on stream bank and gully erosion in agricultural watersheds: What we have learned. Water, 11(7), 1343, 2019.

9. Bernhardt E.S., Palmer M.A., Allan J.D., Alexander G., Barnas K., Brooks S., Carr J., Clayton S., Dahm C., Follstad-Shah J., Galat D., Gloss S., Goodwin P., Hart D., Hassett B., Jenkinson R., Katz S., Kondolf G.M., Lake P.S., Lave R., Meyer J.L., O'Donnell T.K., Pagano L., B. Powell B., Sudduth E., Synthesizing U.S. river restoration efforts. Science 308, 636-637, 2005.

10. Fox G.A., Purvis R.A., Penn C.J., Streambanks: A net source of sediment and phosphorus to streams and rivers. J. Environ. Manage. 181(1), 602-614, 2016.

11. Lawler D.M., Defining the moment of erosion: the principle of thermal consonance timing. Earth Surf. Proc. Landforms, 30, 1597-1615, 2005.

12. Rozenstein O., Karnieli A., Comparison of methods for land-use classification incorporating remote sensing and GIS inputs. Appl. Geogr. 31(2), 533-544, 2011.

13. Chmaj G., Selvaraj H., Distributed processing applications for UAV/drones: A survey. In: Progress in Systems Engineering, Springer, Cham. pp. 449-454, 2015.

14. Pérez E., García P., Monitoring soil erosion by raster images: from aerial photographs to drone taken pictures. Eur. J. Geogr. 7(5), 117- 129, 2017.

15. Koutalakis P., Tzoraki O., Zaimes G., UAVs for hydrologic scopes: Application of a low-cost UAV to estimate surface water velocity by using three different image-based methods. Drones, 3(1), 14, 2019

16. Diebel M.W., Maxted J.T., Robertson D.M., Han S., Vander Zanden M.J., (2001) Landscape planning for agricultural nonpoint source pollution reduction III: Assessing phosphorus and sediment reduction potential. Environ. Manage. 43(1), 69-83, 2001.

17. Riegels N., Pulido-Velazquez M., Doulgeris C., Sturm V., Jensen R., Moller F., Bauer Gottwein P., Systems analysis approach to the design of efficient water pricing policies under the EU Water Framework Directive. J. Water Resour. Plan. Manage. 139(5), 574-582, 2013.

18. Skoulikidis N.T., The environmental state of rivers in the Balkans - a review within the DPSIR framework. Sci. Total Environ. 407(8), 2501-2516, 2009. 
19. Kerr J.T., Ostrovsky M., From space to species: Ecological applications for remote sensing. Trends Ecol. Evol. 18(6), 299-305, 2003.

20. Themistocleous K., Agapiou A., King H.M., King N., Hadjimitsis D.G., More than a flight: the extensive contributions of UAV flights to archaeological research-the case study of curium site in Cyprus. In: Euro-Mediterranean Conference, Springer, Cham, pp. 396-409, 2014.

21. Brutto M.L., Borruso A., D'argenio A., UAV systems for photogrammetric data acquisition of archaeological sites. Intern. J. Herit. Dig. Era 1(1), 7-13, 2012.

22. Verhoeven G., Taking computer vision aloft-archaeological three- dimensional reconstructions from aerial photographs with photoscan. Archaeological Prospection 18(1), 67-73, 2011.

23. Zaimes G.N., Tardio G., Iakovoglou V., Gimenez M., Garcia-Rodriguez J.L., Sangalli P., New tools and approaches to promote soil and water bioengineering in the Mediterranean. Sci. Total Environ. 693, $133677,2019$. 